\title{
Article \\ Contrasting Behavioral and Electrophysiological Responses of Eucryptorrhynchus scrobiculatus and E. brandti (Coleoptera: Curculionidae) to Volatiles Emitted from the Tree of Heaven, Ailanthus altissima
}

\author{
Xiaojian Wen ${ }^{1,3}$, Kailang Yang ${ }^{2,3}$, Jaime C. Piñero ${ }^{4}\left(\mathbb{D}\right.$ and Junbao Wen ${ }^{3, *}$ \\ 1 Laboratory of Forest Pathogen Integrated Biology, Research institute of Forestry New Technology, \\ Chinese Academy of Forestry, Beijing 100091, China; wenxj1016@126.com \\ 2 College of Forestry, Northwest A\&F University, Yangling 712100, China; yangkl@nwafu.edu.cn \\ 3 Beijing Key Laboratory for Forest Pests Control, College of Forestry, Beijing Forestry University, No. 35, \\ Tsinghua East Road, Beijing 100083, China \\ 4 Stockbridge School of Agriculture, University of Massachusetts, Amherst, MA 01003, USA; \\ jpinero@umass.edu \\ * Correspondence: wenjb@bjfu.edu.cn
}

check for updates

Citation: Wen, X.; Yang, K.; Piñero, J.C.; Wen, J. Contrasting Behavioral and Electrophysiological Responses of Eucryptorrhynchus scrobiculatus and E. brandti (Coleoptera: Curculionidae) to Volatiles Emitted from the Tree of Heaven, Ailanthus altissima. Insects 2021, 12, 68. https://doi.org/ $10.3390 /$ insects 12010068

Received: 24 November 2020 Accepted: 11 January 2021 Published: 14 January 2021

Publisher's Note: MDPI stays neutral with regard to jurisdictional clai$\mathrm{ms}$ in published maps and institutional affiliations.

Copyright: () 2021 by the authors. Licensee MDPI, Basel, Switzerland. This article is an open access article distributed under the terms and conditions of the Creative Commons Attribution (CC BY) license (https:// creativecommons.org/licenses/by/ $4.0 /)$.
Simple Summary: Eucryptorrhynchus scrobiculatus (Motschulsky) and E. brandti (Harold) are significant pests of tree of heaven, Ailanthus altissima, often leading to tree death. Monitoring systems that involve host-plant based attractants need to be developed for both insect pest species. Here, we compared the behavioral and electrophysiological responses of E. scrobiculatus and E. brandti to volatiles emitted by various parts of the host plant. Host plant-derived volatiles showed to play a greater role in the foraging behavior of E. brandti than in E. scrobiculatus. Volatile components of phloem were found to be particularly attractive to E. brandti.

Abstract: Eucryptorrhynchus scrobiculatus and E. brandti (Coleoptera: Curculionidae) are host-specific pests of Ailanthus altissima (Mill.) Swingle (Sapindales: Simaroubaceae), causing extensive damage to the host. There are no effective attractants available for pest management. The main aim of this study was to explore the role of host plant-derived volatiles in the behavioral response of both weevil species. In a field experiment, both weevil species showed positive response to phloem, and there was no preference for phloem associated with healthy or injured trees. Significantly more E. brandti adults responded to the olfactory treatments compared to E. scrobiculatus. In a large-arena experiment, both males and females of E. scrobiculatus significantly preferred phloem from the tree trunk while adults of E. brandti responded in significantly greater numbers to tree limbs than to any other parts of host. Females and males of E. scrobiculatus responded positively to all parts of host tested in the Y-tube bioassay, while E. brandti adults were only attracted by the phloem from healthy and injured trees. There were dissimilar electroantennographic responses to compounds such as 1-hexanol and (1S)-(-)- $\beta$-pinene between the two weevil species. This study represents the first report documenting behavioral and electrophysiological responses of E. scrobiculatus and E. brandti to volatiles from various parts of A. altissima and findings may aid efforts to develop attractants.

Keywords: host plant volatiles; semiochemical; feeding selection; behavior; physiology

\section{Introduction}

Plant volatiles are known to play an important role in the host-location process of many species of insect herbivores [1]. Generally, it is believed that species with overlapping habitats have similar ecological niches and thus compete for food resources. Potential limitation in the availability of food resources can lead to differences in the abilities of competing species to exploit resources, often leading to dominance of one species over another [2,3]. However, 
if two species differ slightly in their perception of host plants and ensuing foraging behavior, that may not be the case. Such subtle behavioral or sensory differences might facilitate subtle niche shifts and allow species with similar niches to coexist [4,5].

Eucryptorrhynchus scrobiculatus (Motschulsky) and E. brandti (Harold) (Coleoptera: Curculionidae) are two closely related species of insect herbivores that feed on the tree of heaven, Ailanthus altissima (Mill.) Swingle (Sapindales: Simaroubaceae). Both weevil species are host-specific and adults and larvae feed on different parts of A. altissima [6-8]. For instance, E. scrobiculatus adults feed on annual branches, perennial branches, and petioles, whereas the larvae feed on the root system. In contrast, E. brandti adults feed on the trunk, and larvae develop under the bark, destroying the phloem and xylem as they feed [9-12]. The simultaneous occurrence of the two weevils causes extensive damage to A. altissima, commonly leading to tree death $[10,13,14]$.

Developing effective pest management methods for E. scrobiculatus and E. brandti involving the application of insecticides $[15,16]$ and novel trapping systems $[17,18]$ has been the focus of recent research. In terms of trapping, previously, Yang et al. [17] found that a mixture composed of vinegar, ethanol, and apple juice was attractive to E. scrobiculatus. However, this attractant was not deemed feasible for mass production because it was made of fresh materials, resulting in a short span of attractiveness. Recently, trunk trap nets for E. scrobiculatus and adhesive trunk trap nets for E. brandti were developed [14,17-19]. Trunk trap nets would be more effective if attractants were made available. In order to develop effective attractants for both $E$. scrobiculatus and E. brandti, it is important to understand the role that volatiles of $A$. altissima play on the olfactory response of both weevil species. Previous observations (Wen, unpub. data) indicated that E. scrobiculatus and E. brandti congregate on the bare phloem of tree of heaven in the field, regardless of whether the trees are healthy or injured. Based on these observations, we inferred that volatiles from bare phloem may be attractive to the weevils.

The main goal of this study was to explore the role of host volatiles in the foraging behavior of E. scrobiculatus and E. brandti. In particular, we compared the effects of bare phloem from healthy and injured trees and volatiles emitted by different parts of host plant on the behavioral response of the weevils. In addition, volatile compounds emitted by different parts of $A$. altissima were collected by two methods (headspace solid phase microextraction (HS-SPME) and dynamic headspace method) and analyzed by gas chromatography-mass spectrometry (GC-MS). Finally, the antennal responses of E. scrobiculatus and E. brandti to selected chemical compounds were examined by electroantennography (EAG) and behaviorally using Y-tube olfactometer. These results may provide a reference for the development of attractants that are based on host-plant-derived volatiles.

\section{Materials and Methods}

\subsection{Attractiveness of Bare Phloem of Healthy and Injured Trees to Adult E. scrobiculatus and E. brandti}

The experiment was conducted at Xiaoxingdun village, Pingluo County, Ningxia Hui Autonomous Region ( $\left.38^{\circ} 51^{\prime} 24^{\prime \prime} \mathrm{N}, 106^{\circ} 31^{\prime} 38^{\prime \prime} \mathrm{E}\right)$ in August 2017. Ailanthus altissima trees (tree height was about $10 \mathrm{~m}$; diameter at breast height was about $30 \mathrm{~cm}$; the inter-tree distance was $3.5 \mathrm{~m}$ ) were planted as windbreak near farmland, and they received no fertilizers or pesticides. For this study, we used five trees that had healthy foliage and no signs of weevil infestation and five trees that were seriously infected with both weevil species (i.e., tree branches with some level of defoliation and presence of $>50$ emergence holes on the trunk). Trees were randomly selected.

We quantified the response of both weevil species using a mark-release-recapture method. For each weevil species, previously collected in the field, adults were starved for $12 \mathrm{~h}$ and color-marked with blue oil paint (Jing Dian brand, Beijing Sheng Shi Jing Dian Coating Technology Co., Ltd., Beijing, China) on the elytra before the releases [19]. At 06:00, a square $\left(8 \times 8 \mathrm{~cm}^{2}\right)$ was cut from the trunk at breast height $(1.5 \mathrm{~m})$, and the bark was removed, thereby exposing the xylem and phloem. At 07:00, we released a group of 20 marked E. scrobiculatus and 20 marked E. brandti (mixed sexes) on the ground, $1 \mathrm{~m}$ away 
from each tree. The number of marked weevils arriving to the square area was counted every hour from 08:00 to 19:00 for $48 \mathrm{~h}$. Each weevil was removed and collected in a container after counting.

\subsection{Attractiveness of Various Parts of A. altissima to Adult E. scrobiculatus and E. brandti}

The two experiments described below were conducted under laboratory conditions at Forestry Bureau in Lingwu city.

\subsubsection{Large Still-Air Arena Experiment}

This test quantified the response of adults of each species to four olfactory treatments: (1) annual branches (150 g), (2) freshly cut foliage from seedlings (height: $1 \mathrm{~m}$; weight of plant material used: $150 \mathrm{~g}$ ), (3) one tree limb (length: $10 \mathrm{~cm}$; diam.: $7 \mathrm{~cm}$ ), and (4) phloem $(150 \mathrm{~g})$ from the trunk of healthy A. altissima trees. These four parts of host plant were collected in the morning of a test day and individually placed on white paper plates (diam.: $20 \mathrm{~cm}$ ). An empty plate was used as a control. These five treatments were arranged in a pentagonal shape. The distance between two adjacent treatments was $50 \mathrm{~cm}$. All evaluations took place in the laboratory $\left(28^{\circ} \mathrm{C}, 60 \%\right.$ r.h. $)$, inside a screen cage $\left(2 \times 1.8 \times 1.7 \mathrm{~m}^{3}\right)$ constructed of mosquito netting made of polyester fabric.

For this test, 480 E. scrobiculatus and 480 E. brandti were field-collected and separated in groups of 20 weevils ( 10 E. scrobiculatus and 10 E. brandti) each. All weevils were starved for $12 \mathrm{~h}$ for the observations. Ten E. scrobiculatus and $10 \mathrm{E}$. brandti adults were then released in the center of the experimental arena at 08:00, and the number of weevils arriving to each treatment was recorded every $2 \mathrm{~h}$ from 10:00 to 20:00. Responding weevils were removed at each time interval. At the end of the trial, the experimental arena was cleaned up and left unoccupied overnight. For each trial, fresh plant material and new weevils were used and the position of the olfactory treatments was determined randomly. Trials were repeated 8 times, over a 15-day period.

\subsubsection{Y-Tube Bioassay}

The olfactory response of E. scrobiculatus and E. brandti to different parts of A. altissima was quantified in a Y-tube olfactometer. The olfactory treatments evaluated were (1) phloem $(20 \mathrm{~g})$ from the trunk of healthy trees, (2) phloem $(20 \mathrm{~g})$ from the trunk of highly infested trees (>50 emergence holes on the trunk), (3) freshly cut foliage from seedlings ( $20 \mathrm{~g})$, and (4) pieces of a randomly selected annual branch $(20 \mathrm{~g})$.

Insects. Adult weevils used for this experiment were starved for $24 \mathrm{~h}$ for E. scrobiculatus and $40 \mathrm{~h}$ for $E$. brandti before the bioassay. The length of starvation was chosen based on preliminary observations indicating that when adult $E$. brandti were starved for $24 \mathrm{~h}$ most of them stayed in the base tube and kept still during the test, while similarly-starved adults of E. scrobiculatus readily responded to the stimuli.

Bioassays. The Y-tube olfactometer consisted of a $15 \mathrm{~cm}$ base tube (diam. $=2 \mathrm{~cm})$ with two $12 \mathrm{~cm}$ arms (diam. $=1.5 \mathrm{~cm}$ ) connected at a $75^{\circ}$ angle to two glass spherical traps (diam. $=6 \mathrm{~cm})$ and glass conical flasks $(\mathrm{V}=500 \mathrm{~mL}$ ) that contained the plant material. Moistened activated charcoal-filtered air was pumped by an atmospheric sampler (QC-1S, Beijing Municipal Institute of Labour Protection, Beijing, China) into each of two flasks at a rate of $250 \mathrm{~mL} / \mathrm{min}$. Airflow rate was calibrated using an electronic flow meter. All observations were conducted between 09:00 and 18:00.

At the onset of the bioassays, $20 \mathrm{~g}$ of a particular plant material was placed inside one of the two conical flasks that were connected to the two arms of the Y-tube olfactometer. The second flask was empty and was used as a control. A score line was drawn on each of the two arms of the Y-tube that were associated with either a particular odor treatment or the control arm, at $3 \mathrm{~cm}$ from the intersection. Subsequently, an individual weevil was released at the entrance of the common arm of the Y-tube using a glass vial and the behavioral response was recorded for $5 \mathrm{~min}$. The behavior of the test weevil was classified as "no-choice" if the insect remained in the base tube of the Y-tube olfactometer by the end 
of the observation period. The response was scored as "choice" if the weevil entered one of the two arms of the Y-tube, crossed the score line, and remained there for at least $1 \mathrm{~min}$ [20]. The position of the conical flasks with odor source in relation to each arm was reversed after each test, and all tested weevils were used only once. Eighteen males and eighteen females of E. scrobiculatus and twenty males and 20 females of E. brandti were tested for each treatment. We used a randomized block design with blocking over time. All glass devices were cleaned after each replication by rinsing with anhydrous ethanol and distilled water and then oven-dried.

\subsection{Characterization of Volatiles from Different Parts of A. altissima}

2.3.1. Collection of Plant Volatiles by Headspace-Solid Phase Microextraction (HS-SPME)

Volatile collections focused on phloem from healthy and infected trees using HS-SPME. Tree limbs (length: $1 \mathrm{~m}$; diam.: $7 \mathrm{~cm}$ ) from healthy and infected trees were obtained, properly packaged to keep them cool, and immediately taken from Ningxia to Beijing. Phloem (10 g) was obtained by cutting $0.5 \mathrm{~cm}$ sections. Then, the phloem was placed into the extraction bottle $(20 \mathrm{~mL})$. The volatile compounds were collected from extraction bottles using solid phase microextraction (SPME) fiber (50/30 $\mu \mathrm{m}$ DVB/CARBOXEN/PDMS, Supelco, Inc., Bellefonte, PA, USA). The SPME fiber was placed in the inlet of the gas chromatograph and purged at $260{ }^{\circ} \mathrm{C}$ for $30 \mathrm{~min}$ before each experiment, then the fiber was inserted into the bottle and placed above the materials, extracting for $30 \mathrm{~min}$ at $70{ }^{\circ} \mathrm{C}$. After extraction, the fiber was withdrawn from the bottle and inserted into the inlet rapidly. The fiber was remained for $1 \mathrm{~min}$ after it was extended, and then desorbed at $260{ }^{\circ} \mathrm{C}$ for $5 \mathrm{~min}$. Finally, the fiber was removed for GC-MS (GCMS-QP2010 SE, Shimadzu, Kyoto, Japan) analysis.

\subsubsection{Collection of Plant Volatiles by Dynamic Headspace Method}

Volatiles emitted from (1) phloem from healthy and infected trees, (2) annual branches, and (3) foliage from seedlings were sampled from the field and collected by dynamic headspace method at the Forestry Bureau in Lingwu city. In the laboratory, each plant part was placed inside the collection bag (Oven Bags Turkey Size, Reynolds Consumer Products, Inc., Lake Forest, IL, USA) and tied tightly. After the air in the bag was drained by the atmospheric sampler (QC-1S, Beijing Municipal Institute of Labour Protection), the filtered air was pumped into the bag through the glass tube with activated charcoal using the atmospheric sampler. The other corner of the bag was attached to a glass tube with $70 \mathrm{mg}$ of Porapak Q (80-100 mesh), the adsorbents were sandwiched between glass wool in the glass tube. The atmospheric sampler pumped clean air at a flow rate of $150 \mathrm{~mL} / \mathrm{min}$. Volatiles were collected by the adsorbents for $24 \mathrm{~h}$ and were then eluted with $800 \mu \mathrm{L}$ of n-hexane. The eluent was kept at $-20{ }^{\circ} \mathrm{C}$ and brought back to Beijing for analysis. Volatiles of empty collection bags were collected as a control.

Volatiles collected by HS-SPME and dynamic headspace method were analyzed by GC-MS-QP2010 SE (Shimadzu, Kyoto, Japan) following the same procedure. The GC was equipped with a Restek Rtx-5MS capillary column $(30 \mathrm{~m} \times 0.25 \mathrm{~mm} \times 0.25 \mu \mathrm{m})$. Helium was used as the carrier gas at a constant flow rate of $1 \mathrm{~mL} / \mathrm{min}$, the injection volume was $1.0 \mu \mathrm{L}$ in the split mode with a $40: 1$ split. The oven temperature started at $50{ }^{\circ} \mathrm{C}$, and was increased at $6{ }^{\circ} \mathrm{C} / \mathrm{min}$ to $180{ }^{\circ} \mathrm{C}$ and held for $6 \mathrm{~min}$, then increased at $10{ }^{\circ} \mathrm{C} / \mathrm{min}$ to $280{ }^{\circ} \mathrm{C}$ and held for $10 \mathrm{~min}$. The mass spectra were recorded in the electron impact mode at $70 \mathrm{eV}$ (source at $220^{\circ} \mathrm{C}$, scanned mass range: $29-500 \mathrm{~m} / \mathrm{z}$ ). Data analyses were performed using GCMS solution 4.1.1 (Shimadzu, Japan) with the National Institute of Standards and Technology (NIST) database. The relative content of each volatile compound was identified by peak area calculated by the normalized method [21].

\subsection{Electroantennogram Responses}

The antennal response of both sexes of adult E. scrobiculatus and E. brandti to the synthetic olfactory stimuli were quantified by electroantennogram (EAG) using the most abundant compounds identified in the previous study. For this experiment we evaluated 
1-hexanol (98\%; Tianjin Guangfu Fine Chemical Research Institute, Tianjin, China), (1S)(-)- $\beta$-pinene (98\%; Shanghai Macklin Biochemical Co., Ltd., Shanghai, China), (1R)-(+)- $\alpha-$ pinene (99\%; Shanghai Aladdin Bio-Chem Technology Co., Ltd., Shanghai, China), isooctyl alcohol (99\%) and liquid paraffin (both were purchased from Tianjin Yongda Chemical Reagent Co., Ltd., Tianjin, China), cis-3-hexen-1-ol (98\%, Shanghai Yuanye Biotechnology Co., Ltd., Shanghai, China). Each compound was tested singly at five concentrations (100, $10,1,0.1,0.01 \mu \mathrm{g} / \mu \mathrm{L})$ using liquid paraffin as solvent. The material was applied $(10 \mu \mathrm{L})$ to a filter paper strip $\left(5 \times 25 \mathrm{~mm}^{2}\right)$. Because the weevils showed steady peaks in response to cis-3-hexen-1-ol through preliminary test, cis-3-hexen-1-ol (30 $\mu \mathrm{g} / \mu \mathrm{L})$ was selected as a reference compound. The control stimulus was liquid paraffin.

The experiment was carried out as described by Ren [22]. Briefly, weevil antennae were cut off as close as possible to the base of the clavola and took $0.5 \mathrm{~mm}$ off the terminal. Then, the antenna was positioned in parallel across a forked metal electrode using Spectra 360 electrode gel (Parker Laboratories Inc., Orange, NJ, USA). The electrode was connected via an interface box (INR-II, Syntech, Hilve rsum, The Netherlands) to a signal acquisition system (IDAC-4, Syntech, Hilve rsum, The Netherlands) connected to a computer using AutoSpike software (Syntech, Hilve rsum, The Netherlands). Both constant airflow and air puffs were generated with a stimulus flow controller (CS-55; Syntech, Hilve rsum, The Netherlands). The controller including a glass tube (2 cm diameter), with an outlet facing towards the antenna at a distance of $1 \mathrm{~cm}$, provided airflow at $30 \mathrm{~mL} / \mathrm{s}$. The glass tube presented one lateral hole that permitted the delivery of the stimulus puff inside the tube with the aim of a glass Pasteur pipette attached to Tygon tubes leading to an air source programmed to deliver a $0.5 \mathrm{~s}$ pulse at $30 \mathrm{~mL} / \mathrm{s}$. The tested odor was carried out by continuous flow of clean air through a Pasteur pipette containing the filter paper strip soaked in the compound. The chemical stimuli were tested randomly from low concentration to high concentration for each compound, with a stimulus duration time of $0.5 \mathrm{~s}$, followed by a $1 \mathrm{~min}$ purge with purified air. Liquid paraffin and cis-3-hexen-1-ol $(30 \mu \mathrm{g} / \mu \mathrm{L})$ were successively applied at the beginning and at the end of each compound. EAG responses were measured as the maximum amplitude of depolarization $(\mathrm{mV})$. The response to the solvent control was subtracted from all of the initial responses, and the normalized EAG responses were presented as the ratio of the EAG responses of tested compound to the EAG responses of the standard compound. Each compound was tested on 5 individual male and female antennae.

\subsection{Data Analyses}

We compared the response of each weevil species to bare phloem of healthy and injured tree by means of two-way Analysis of Variance (ANOVA). One-way ANOVA was used to compare the behavioral responses of E. scrobiculatus and E. brandti to different parts of A. altissima. Whenever appropriate, post-hoc comparisons were done using Duncan's new multiple range test $(p<0.05)$. For the experiments involving Y-tube olfactometer, onesample $\chi^{2}$ tests were conducted on the numbers of test weevils of each species that made a choice to test the null hypothesis of no preference for a particular synthetic compound vs. clean air. EAG response data for different concentrations of each compound for the same sex were analyzed by one-way ANOVA followed by Duncan's new multiple range test $(p<0.05)$. We compared EAG responses between female and male E. scrobiculatus and E. brandti for each treatment using $t$-tests. Parametric data were checked for the assumption of normality and homoscedasticity. All analyses were conducted using IBM SPSS statistics (version: 23; SPSS Inc., Chicago, IL, USA).

\section{Results}

\subsection{Attractiveness of Various Parts of A. altissima to Adult E. scrobiculatus and E. brandti}

In the first series of experiments, we evaluated the level of attractiveness of bare phloem of healthy and injured A. altissima trees to adults of both weevil species. In the field study, we recovered $10 \%$ and $14 \%$ of the marked E. scrobiculatus adults and $37 \%$ and 
$35 \%$ of the marked E. brandti adults from bare phloem of injured trees and healthy trees, respectively. The response of the weevils differed significantly between species ( $F=17.07$, $\mathrm{df}=1, p<0.05$ ), but the state of the tree (i.e., injured vs. healthy) had no effect on the number of weevils responding for each species $(F=0.03, \mathrm{df}=1, p=0.865)$. The interaction term (weevil species $\times$ state of tree) was non-significant $(F=0.27, \mathrm{df}=1, p=0.613$ ).

In the large-arena experiment, there were significant differences in the level of response of E. scrobiculatus and E. brandti to the various parts of A. altissima. Adults of E. scrobiculatus significantly preferred phloem from the trunk $(F=12.57, \mathrm{df}=3,31, p<0.05)$. E. brandti adults responded in significantly greater numbers to the tree limb than to any other plant material. Phloem from trunk ranked second in preference, and this material was more attractive to the weevils than annual branches and seedling foliage $(F=13.36, \mathrm{df}=3,27$, $p<0.05$ ) (Figure 1).

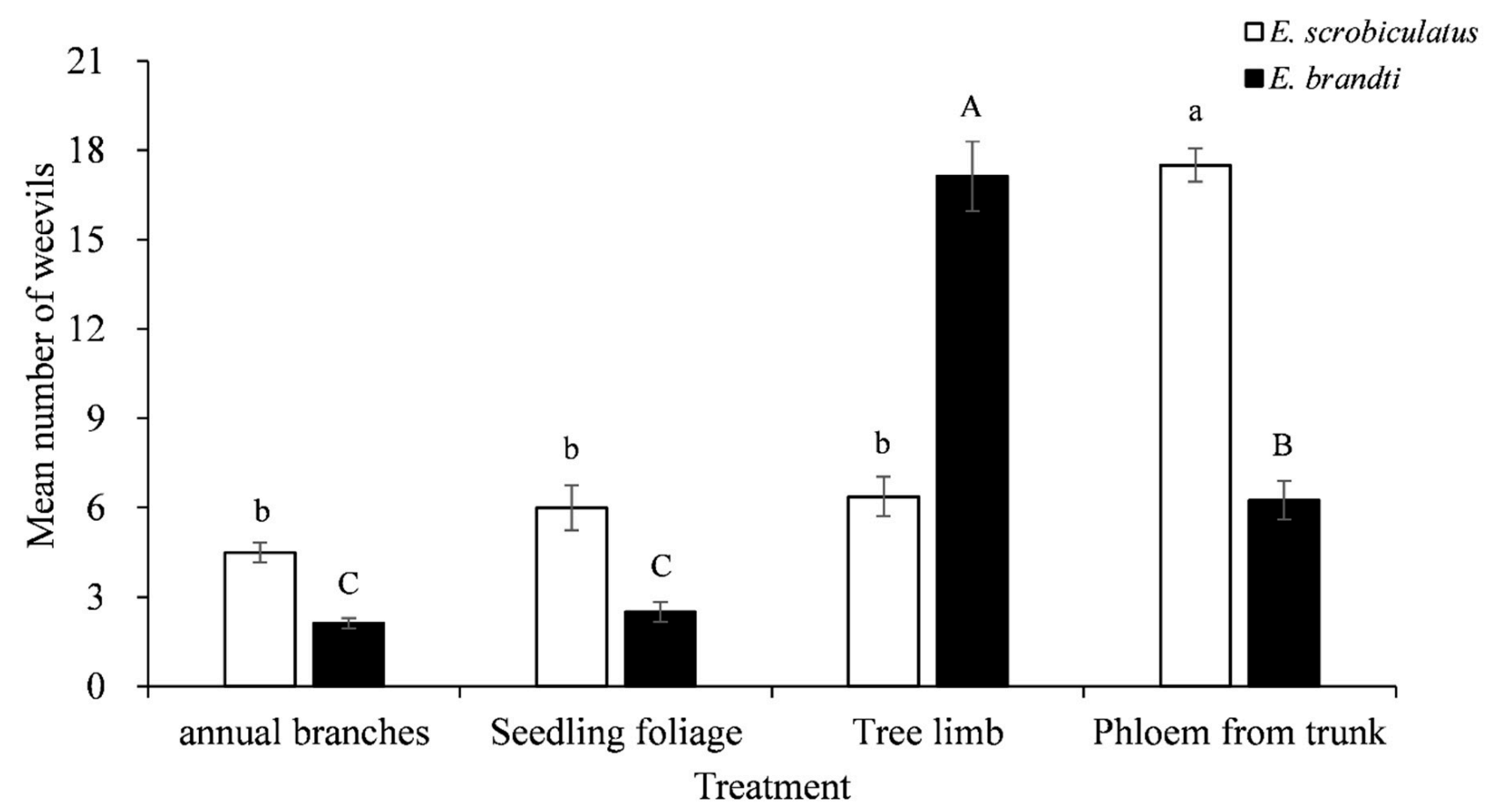

Figure 1. Response of adult E. scrobiculatus and E. brandti to various types of plant material from A. altissima in the largearena experiment. Means $( \pm \mathrm{SE})$ were calculated from the number of weevils responding to each treatment. For each weevil species, different letters above bars denote significant differences according to ANOVA and Duncan's new multiple range test at $p=0.05$.

Results from the Y-tube olfactometer revealed that E. scrobiculatus females responded positively to all types of plant material that they were exposed to when compared with air (healthy phloem versus air: $\chi^{2}=11.267, \mathrm{df}=1, p<0.01$; injured phloem versus air: $\chi^{2}=10.889, \mathrm{df}=1, p<0.01$; annual branches versus air: $\chi^{2}=9, \mathrm{df}=1, p<0.01$ ). Similar results were found for E. scrobiculatus males (injured phloem versus air: $\chi^{2}=12.25, \mathrm{df}=1$, $p<0.01$; seedling foliage versus air: $\chi^{2}=12.25, \mathrm{df}=1, p<0.01$; annual branches versus air: $\chi^{2}=12.25, \mathrm{df}=1, p<0.01$ ) (Figure 2). 


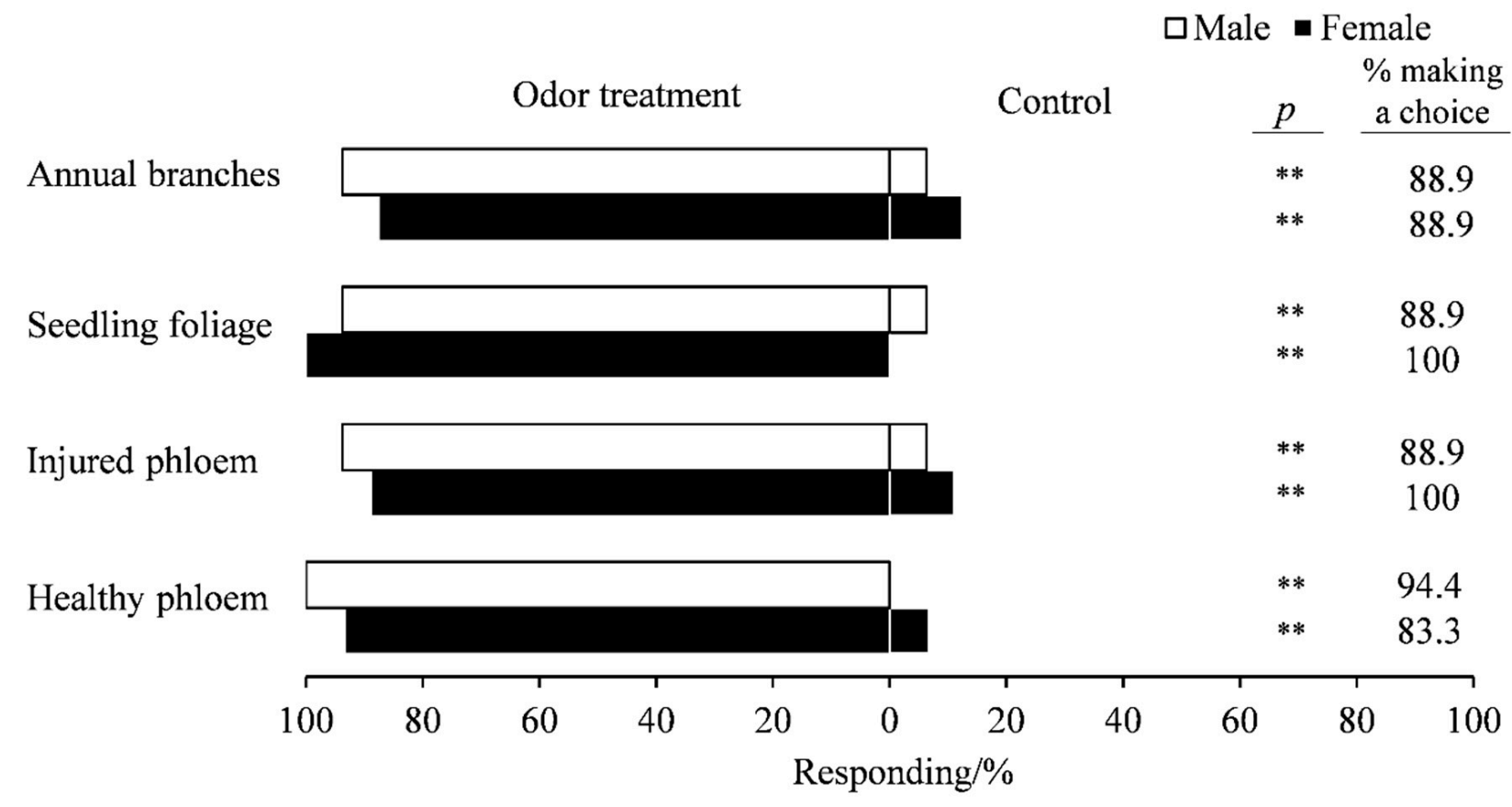

Figure 2. Response of E. scrobiculatus females $(n=18)$ and males $(n=18)$ to different parts of $A$. altissima in the Y-tube olfactometer. Injured phloem $=$ phloem from injured trees; healthy phloem $=$ phloem from healthy trees. $p$-values are based on Pearson's chi-square test: ${ }^{* *}, p<0.01$.

Contrasting gender responses were recorded for E. brandti. Female and male weevils showed a significant preference for phloem regardless of the condition of the tree (healthy phloem: female: $\chi^{2}=12.25 ; p<0.01$; males: $100 \%$ of the males responded to healthy phloem; injured phloem: female: $\chi^{2}=14.22 ; p<0.01$; male: $\left.\chi^{2}=4 ; p<0.05\right)$ when compared with air. However, a repellent effect was noted for females, which significantly selected the arm associated with clean air compared with the arm containing foliage from seedlings $\left(x^{2}=5.33 ; p<0.05\right)$ whereas males showed a significant preference for seedling foliage. While no significant differences were observed in the response of females toward volatiles emitted from annual branches $\left(\chi^{2}=2.273, p>0.05\right)$, it exerted a significant repellent effect on males $\left(\chi^{2}=6.25 ; p>0.05\right)$ (Figure 3$)$.

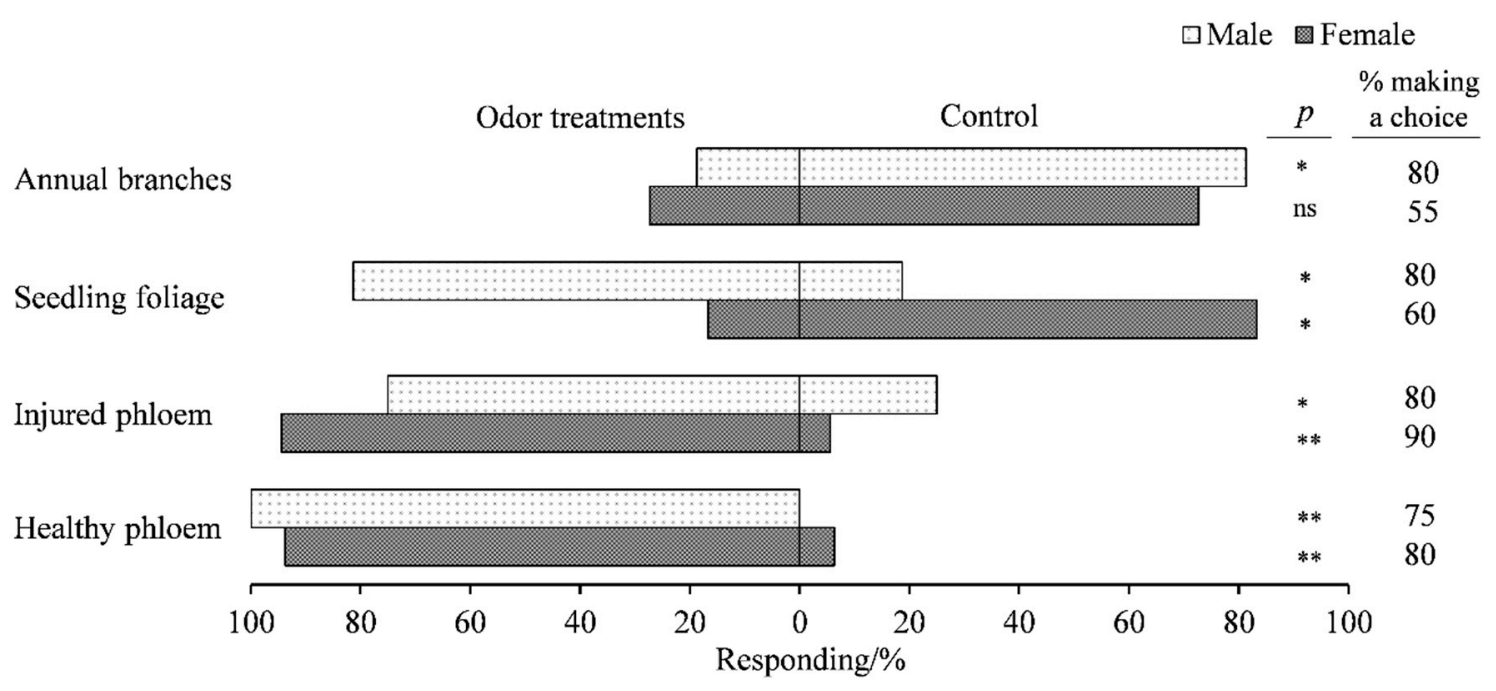

Figure 3. Response of E. brandti females $(n=20)$ and males $(n=20)$ to different parts of A. altissima in the Y-tube olfactometer. Injured phloem $=$ phloem from injured trees; healthy phloem $=$ phloem from healthy trees. $p$-values are based on Pearson's chi-square test: ${ }^{*}, p<0.05 ;{ }^{* *}, p<0.01 ; \mathrm{ns}, p \geq 0.05$. 


\subsection{Characterization of Volatiles from Different Parts of A. altissima}

The volatiles from phloem from healthy and infested trees were collected by HS-SPME. Twenty-three and thirty-five components were identified in the volatiles of phloem from healthy and injured tree, respectively. There were more types of compounds in the volatiles of phloem from injured trees than from healthy trees (Table 1).

Table 1. Volatile compounds of healthy and injured phloem of A. altissima by headspace solid phase microextraction (HS-SPME).

\begin{tabular}{|c|c|c|c|c|}
\hline \multirow{2}{*}{ Number } & \multirow{2}{*}{ Name } & \multirow{2}{*}{ CAS } & \multicolumn{2}{|c|}{ Area under Peak } \\
\hline & & & Healthy Phloem & Injured Phloem \\
\hline 1 & $(1 R)-(+)-\alpha$-Pinene & $7785-70-8$ & 599,387 & 302,479 \\
\hline 2 & Camphene & $79-92-5$ & 289,369 & \\
\hline 3 & $\beta$-Phellandrene & $555-10-2$ & 78,859 & \\
\hline 4 & $(1 S)-(-)-\beta$-Pinene & $18172-67-3$ & 358,576 & \\
\hline 5 & Myrcene & $123-35-3$ & & $1,360,591$ \\
\hline 6 & $(+)-(4 R)$-Limonene & $5989-27-5$ & & $1,898,791$ \\
\hline 7 & $\beta$-Ocimene & $3338-55-4$ & & $4,851,574$ \\
\hline 8 & $(+)$-2-Carene & $554-61-0$ & & $1,210,188$ \\
\hline 9 & $\alpha$-Cubebene & $17699-14-8$ & & $12,832,275$ \\
\hline 10 & Copaene & $3856-25-5$ & & $10,567,644$ \\
\hline 11 & $\beta$-Caryophyllene & $87-44-5$ & 65,276 & $42,295,799$ \\
\hline 12 & $\alpha$-Humulene & $6753-98-6$ & & $7,472,179$ \\
\hline 13 & $\beta$-Copaene & & & $2,172,542$ \\
\hline 14 & $(+)$ - $\delta$-Cadinene & $483-76-1$ & & $1,005,043$ \\
\hline 15 & 1-Calamenene & $483-77-2$ & & 288,668 \\
\hline 16 & Caryophyllene oxide & $1139-30-6$ & & 616,535 \\
\hline 17 & 2-Xylene & $95-47-6$ & 184,083 & $1,196,424$ \\
\hline 18 & p-Xylene & $106-42-3$ & 332,852 & \\
\hline 19 & 1-Ethyl-4-methylbenzene & $622-96-8$ & 68,356 & \\
\hline 20 & 3-Ethyltoluene & $620-14-4$ & & 972,029 \\
\hline 21 & 2-Ethyltoluene & $611-14-3$ & & 560,994 \\
\hline 22 & Mesitylen & $108-67-8$ & 75,378 & $5,228,481$ \\
\hline 23 & 1,2,3-Trimethylbenzene & $526-73-8$ & 69,816 & 566,908 \\
\hline 24 & 1-Methyl-3-propylbenzene & $1074-43-7$ & & 445,924 \\
\hline 25 & 2-Ethyl-p-xylene & $1758-88-9$ & & 981,883 \\
\hline 26 & 4-Ethyl-m-xylene & $874-41-9$ & & 785,844 \\
\hline 27 & 1,2,3,4-Tetramethylbenzene & $488-23-3$ & & 520,840 \\
\hline 28 & $1,2,3,5$-Tetramethylbenzene & $527-53-7$ & & 864,315 \\
\hline 29 & $1,2,4,5$-Tetramethylbenzene & 95-93-2 & & 303,672 \\
\hline 30 & 3-Methylcyclopentanol & $18729-48-1$ & 159,700 & \\
\hline 31 & cis-3-Hexen-1-ol & $928-96-1$ & 863,559 & \\
\hline 32 & Cyclohexanol & $108-93-0$ & 333,474 & \\
\hline 33 & 1-Hexanol & $111-27-3$ & $4,902,291$ & $7,042,158$ \\
\hline 34 & 2-Ethyl-1-hexanol & $104-76-7$ & 515,699 & \\
\hline 35 & 3,3-Dimethyl-1,2-epoxybutane & $2245-30-9$ & $1,169,014$ & \\
\hline 36 & 2,4-Dimethylhexane & $589-43-5$ & 110,544 & \\
\hline 37 & Tetradecane & $629-59-4$ & 57,964 & \\
\hline 38 & $d$-Camphor & $464-49-3$ & 59,699 & \\
\hline 39 & 2-Hendecanone & $112-12-9$ & & 331,169 \\
\hline 40 & Tetradecanal & $124-25-4$ & & 644,070 \\
\hline 41 & Pentadecanal & $2765-11-9$ & & 286,561 \\
\hline 42 & Dibutyl ether & $142-96-1$ & $1,178,162$ & $1,392,083$ \\
\hline 43 & 1,2-Dimethoxybenzene & $91-16-7$ & & 540,650 \\
\hline 44 & Dibutyl phthalate & 84-74-2 & 272,435 & 554,530 \\
\hline 45 & Oxetane, 3-(1-methylethyl)- & $10317-17-6$ & 85,020 & \\
\hline 46 & Di-tert-butyl peroxide & $110-05-4$ & 119,142 & \\
\hline 47 & 4-Hydroxy-3-methylbutanal & $56805-34-6$ & & 972,544 \\
\hline 48 & Aciphyllene & $87745-31-1$ & & 330,730 \\
\hline 49 & Cubebene & $13744-15-5$ & & $2,455,168$ \\
\hline 50 & (+)-Epi-bicyclosesquiphellandrene & $54274-73-6$ & & 367,917 \\
\hline
\end{tabular}


A total of 43 compounds were identified from different parts of A. altissima by dynamic headspace method. Fourteen volatile compounds were identified from phloem from healthy tree, and the main components of volatiles included $\beta$-caryophyllene (33.88\%), 2-phenylethyl-1,1,2,2-d4-amine (17.52\%), (-)-camphene (8.22\%) and 1-tridecanol (6.81\%), accounting for $66.43 \%$ of the total amount. Twenty-two components were identified in the volatiles of phloem from injured tree, and the primary compounds were 1-tetradecene $(17.58 \%), 1$-tridecene $(10.05 \%), \beta$-copaene $(8.94 \%)$, and $n$-hendecane $(6.91 \%)$, accounting for $43.48 \%$ of the total amount. Eleven volatile compounds were identified from seedling foliage, and the main compounds included $\beta$-copaene $(41.72 \%), \beta$-caryophyllene (26.94\%), $\alpha$-farnesene $(12.74 \%)$, and leaf acetate $(11.7 \%)$, accounting for $93.1 \%$ of the total amount. Eight volatile compounds were identified from annual branches, and the main compounds included $\beta$-copaene (41.43\%), $\alpha$-farnesene (22.29\%), $\beta$-caryophyllene (21.63\%), and $\beta$-elemene $(8.24 \%)$, accounting for $93.59 \%$ of the total amount (Table 2 ).

Table 2. Volatile compounds of different parts of A. altissima by dynamic headspace method.

\begin{tabular}{|c|c|c|c|c|c|c|}
\hline \multirow[b]{2}{*}{ Number } & \multirow[b]{2}{*}{ Name } & \multirow[b]{2}{*}{ CAS } & \multicolumn{4}{|c|}{ Relative Content (in \%) } \\
\hline & & & $\begin{array}{l}\text { Healthy } \\
\text { Phloem }\end{array}$ & $\begin{array}{l}\text { Injured } \\
\text { Phloem }\end{array}$ & $\begin{array}{l}\text { Seedling } \\
\text { Foliage }\end{array}$ & $\begin{array}{c}\text { Annual } \\
\text { Branches }\end{array}$ \\
\hline 1 & $(1 R)-(+)-\alpha$-Pinene & $7785-70-8$ & 2.92 & & 0.53 & \\
\hline 2 & $(-)$-Camphene & $5794-04-7$ & 8.22 & & & \\
\hline 3 & Camphene & $79-92-5$ & & & 0.97 & \\
\hline 4 & $\beta$-Pinene & $127-91-3$ & 5.49 & & & \\
\hline 5 & $(1 S)-(-)-\beta$-Pinene & $18172-67-3$ & & & 0.54 & \\
\hline 6 & 1-Decene & $872-05-9$ & & 1.7 & & \\
\hline 7 & $(+)-(4 R)$-Limonene & $5989-27-5$ & & 1.21 & & \\
\hline 8 & 1-Undecene & $821-95-4$ & & 2.01 & & \\
\hline 9 & 1-Tridecene & $2437-56-1$ & & 10.05 & & \\
\hline 10 & $\alpha$-Pinene & $3856-25-5$ & & 1.44 & 0.93 & 0.74 \\
\hline 11 & $\beta$-Bourbonene & $5208-59-3$ & & 4.33 & & \\
\hline 12 & 1-Tetradecene & $1120-36-1$ & & 17.58 & & \\
\hline 13 & $\beta$-Elemene & $515-13-9$ & & & & 8.24 \\
\hline 14 & $\beta$-Caryophyllene & $87-44-5$ & 33.88 & & 26.94 & 21.63 \\
\hline 15 & 1-Pentadecene & $13360-61-7$ & 2.54 & & & \\
\hline 16 & $\beta$-Copaene & & & 8.94 & 41.72 & 41.43 \\
\hline 17 & $\alpha$-Farnesene & $502-61-4$ & & & 12.74 & 22.29 \\
\hline 18 & 1-Heptadecene & $6765-39-5$ & & 2.91 & & \\
\hline 19 & 2,4-Dimethylheptane & $2213-23-2$ & & 1.62 & & \\
\hline 20 & n-Hendecane & $1120-21-4$ & & 6.91 & & \\
\hline 21 & Dodecane & $112-40-3$ & & 1.2 & & \\
\hline 22 & n-Tridecane & $629-50-5$ & 2.88 & 5.45 & & \\
\hline 23 & Tetradecane & $629-59-4$ & 3.34 & 2.67 & & \\
\hline 24 & n-Pentadecane & $629-62-9$ & 3.13 & 6.01 & & \\
\hline 25 & n-Heptadecane & $629-78-7$ & & 1.12 & & \\
\hline 26 & 1-Dodecanol & $112-53-8$ & & 11 & & \\
\hline 27 & 1-Tridecanol & $112-70-9$ & 6.81 & & & \\
\hline 28 & 1-Pentadecanol & $629-76-5$ & & 1.21 & & \\
\hline 29 & Ethyl 2-methylbutyrate & $7452-79-1$ & & & 2.24 & \\
\hline 30 & Ethyl tiglate & $5837-78-5$ & & & 0.67 & \\
\hline 31 & Leaf acetate & $3681-71-8$ & & & 11.7 & 1.65 \\
\hline 32 & Bis(2-ethylhexyl) adipate & $103-23-1$ & & & & 0.63 \\
\hline 33 & Carvacrol & $499-75-2$ & & & & 3.39 \\
\hline 34 & 2,4-Di-tert-butylphenol & $96-76-4$ & 2.39 & & & \\
\hline 35 & 2-Phenylethyl-1,1,2,2-d4-amine & $876-20-0$ & 17.52 & & & \\
\hline
\end{tabular}


Table 2. Cont.

\begin{tabular}{|c|c|c|c|c|c|c|}
\hline \multirow[b]{2}{*}{ Number } & \multirow[b]{2}{*}{ Name } & \multirow[b]{2}{*}{ CAS } & \multicolumn{4}{|c|}{ Relative Content (in \%) } \\
\hline & & & $\begin{array}{l}\text { Healthy } \\
\text { Phloem }\end{array}$ & $\begin{array}{l}\text { Injured } \\
\text { Phloem }\end{array}$ & $\begin{array}{l}\text { Seedling } \\
\text { Foliage }\end{array}$ & $\begin{array}{l}\text { Annual } \\
\text { Branches }\end{array}$ \\
\hline 36 & Cuminaldehyde & $122-03-2$ & 6.1 & & & \\
\hline 37 & 4-Ethylbenzaldehyde & $4748-78-1$ & 2.15 & & & \\
\hline 38 & Phenylethylene & $100-42-5$ & & 6.12 & & \\
\hline 39 & Isobutylbenzene & & & & 1.04 & \\
\hline 40 & Hexane,2,2,3,3-tetramethyl- & $13475-81-5$ & & 1.59 & & \\
\hline 41 & 2-Pentylfuran & $3777-69-3$ & & 2.82 & & \\
\hline 42 & 4-Ethylcumen & $4218-48-8$ & & 2.11 & & \\
\hline 43 & 5-Ethylundecane & $17453-94-0$ & 2.63 & & & \\
\hline
\end{tabular}

The number of volatile components from phloem of injured trees exceeded that from phloem of healthy tree as determined by the HS-SPME and dynamic headspace methods. The main components were alkenes (76.04\%) and alcohols (56.69\%) in phloem of injured and healthy tree by HS-SPME, respectively. The main volatile components of different parts of $A$. altissima by dynamic headspace method were alkenes, especially for seedling foliage (84.37\%) and annual branches (94.33\%). Besides, alkenes accounted for 53.05\% and $50.17 \%$ of the total volatile compounds in phloem of healthy and injured trees, respectively (Tables 1 and 2).

\subsection{Electroantennogram Responses}

We analyzed EAG responses of female and male of E. scrobiculatus and E. brandti to five selected volatile compounds emitted by A. altissima phloem. The EAG responses to each compound differed significantly between female and male E. scrobiculatus and E. brandti. In particular, female responses to 1-hexanol were significantly greater than those of males at moderate doses (e.g., at $0.1,1$, and $10 \mu \mathrm{g} / \mu \mathrm{L}$ ) in E. scrobiculatus and E. brandti. Male responses to (1S)-(-)- $\beta$-pinene were significantly greater than those of females at higher doses (e.g., at 0.1, 1, 10, and $100 \mu \mathrm{g} / \mu \mathrm{L}$ ) in E. brandti (Table 3, Figures 4 and 5).

Table 3. Dose-dependent electroantennography (EAG) responses of E. scrobiculatus and E. brandti to different compounds. Means $( \pm \mathrm{SE})$ followed by the same letter in the same line are not significantly different $(p<0.05)$.

\begin{tabular}{|c|c|c|c|c|c|c|}
\hline \multirow{2}{*}{ Compound } & \multirow{2}{*}{ Insect } & \multicolumn{5}{|c|}{ Mean EAG Responses ( \pm SE) } \\
\hline & & $0.01 \mu \mathrm{g} / \mu \mathrm{L}$ & $0.1 \mu \mathrm{g} / \mu \mathrm{L}$ & $1 \mu \mathrm{g} / \mu \mathrm{L}$ & $10 \mu \mathrm{g} / \mu \mathrm{L}$ & $100 \mu \mathrm{g} / \mu \mathrm{L}$ \\
\hline \multirow{4}{*}{ Isooctyl alcohol } & ESF & $0.71 \pm 0.07 c$ & $1.04 \pm 0.14 \mathrm{bc}$ & $0.72 \pm 0.1 c$ & $1.64 \pm 0.14 \mathrm{a}$ & $1.33 \pm 0.29 \mathrm{ab}$ \\
\hline & ESM & $0.82 \pm 0.04 \mathrm{a}$ & $0.33 \pm 0.05 b$ & $0.42 \pm 0.22 b$ & $0.31 \pm 0.1 b$ & $0.68 \pm 0.02 \mathrm{ab}$ \\
\hline & $\mathrm{EBF}$ & $0.63 \pm 0.14 \mathrm{abc}$ & $0.43 \pm 0.08 b c$ & $0.81 \pm 0.08 \mathrm{a}$ & $0.33 \pm 0.08 c$ & $0.69 \pm 0.09 \mathrm{ab}$ \\
\hline & EBM & $0.67 \pm 0.17 \mathrm{ab}$ & $0.25 \pm 0.12 b$ & $0.43 \pm 0.14 \mathrm{ab}$ & $1.04 \pm 0.21 \mathrm{a}$ & $0.85 \pm 0.3 \mathrm{ab}$ \\
\hline \multirow{4}{*}{ cis-3-Hexen-1-ol } & ESF & $0.35 \pm 0.12 \mathrm{ab}$ & $0.62 \pm 0.05 \mathrm{ab}$ & $0.79 \pm 0.18 a$ & $0.24 \pm 0.18 b$ & $0.7 \pm 0.08 \mathrm{a}$ \\
\hline & ESM & $0.7 \pm 0.03 \mathrm{ab}$ & $0.34 \pm 0.11 b$ & $0.79 \pm 0.19 a$ & $0.81 \pm 0.14 \mathrm{a}$ & $0.47 \pm 0.06 \mathrm{ab}$ \\
\hline & EBF & $0.77 \pm 0.22 \mathrm{a}$ & $0.03 \pm 0.01 b$ & $0.84 \pm 0.07 a$ & $1.06 \pm 0.21 \mathrm{a}$ & $0.88 \pm 0.12 a$ \\
\hline & EBM & $0.4 \pm 0.13 b$ & $0.43 \pm 0.09 b$ & $0.4 \pm 0.04 b$ & $0.94 \pm 0.09 a$ & $0.65 \pm 0.12 \mathrm{ab}$ \\
\hline \multirow{4}{*}{ 1-Hexanol } & ESF & $0.85 \pm 0.15 c$ & $2.1 \pm 0.05 a$ & $1.16 \pm 0.04 b$ & $0.8 \pm 0.07 c$ & $0.89 \pm 0.11 b c$ \\
\hline & ESM & $0.16 \pm 0.03 \mathrm{~d}$ & $1.1 \pm 0.01 \mathrm{a}$ & $0.74 \pm 0.03 b$ & $0.23 \pm 0.08 \mathrm{~d}$ & $0.5 \pm 0.05 c$ \\
\hline & $\mathrm{EBF}$ & $0.46 \pm 0.16 \mathrm{~d}$ & $1.05 \pm 0.11 b c$ & $1.64 \pm 0.12 \mathrm{a}$ & $1.25 \pm 0.13 b$ & $0.75 \pm 0.05 \mathrm{~cd}$ \\
\hline & EBM & $0.58 \pm 0.04 a b$ & $0.56 \pm 0.07 \mathrm{ab}$ & $0.61 \pm 0.16 \mathrm{ab}$ & $0.47 \pm 0.01 b$ & $0.83 \pm 0.08 \mathrm{a}$ \\
\hline \multirow{4}{*}{$(1 S)-(-)-\beta$-Pinene } & ESF & $0.98 \pm 0.05 b$ & $0.23 \pm 0.05 c$ & $0.95 \pm 0.1 b$ & $2.1 \pm 0.36 a$ & $0.96 \pm 0.15 b$ \\
\hline & ESM & $0.49 \pm 0.09 b c$ & $0.33 \pm 0.07 c$ & $1.43 \pm 0.19 a$ & $0.85 \pm 0.14 \mathrm{~b}$ & $1.48 \pm 0.15 a$ \\
\hline & EBF & $0.67 \pm 0.04 a$ & $0.29 \pm 0.05 b$ & $0.2 \pm 0.06 b c$ & $0.08 \pm 0.0048 \mathrm{~cd}$ & $0.05 \pm 0.0043 \mathrm{~d}$ \\
\hline & EBM & $0.45 \pm 0.05 a$ & $0.59 \pm 0.05 a$ & $0.58 \pm 0.07 a$ & $0.51 \pm 0.09 \mathrm{a}$ & $0.67 \pm 0.05 \mathrm{a}$ \\
\hline \multirow{4}{*}{$(1 R)-(+)-\alpha$-Pinene } & ESF & $1.9 \pm 0.07 a$ & $0.91 \pm 0.06 b$ & $1.65 \pm 0.1 \mathrm{a}$ & $0.76 \pm 0.13 b$ & $1.65 \pm 0.15 a$ \\
\hline & ESM & $0.8 \pm 0.11 a$ & $0.44 \pm 0.1 b$ & $0.77 \pm 0.06 b$ & $0.82 \pm 0.05 b$ & $0.83 \pm 0.08 b$ \\
\hline & EBF & $0.75 \pm 0.19 b$ & $1.19 \pm 0.12 \mathrm{a}$ & $1.44 \pm 0.16 a$ & $1.25 \pm 0.09 a$ & $0.39 \pm 0.08 b$ \\
\hline & EBM & $0.28 \pm 0.03 b$ & $0.3 \pm 0.1 b$ & $0.69 \pm 0.24 b$ & $1.54 \pm 0.19 \mathrm{a}$ & $0.23 \pm 0.18 b$ \\
\hline
\end{tabular}



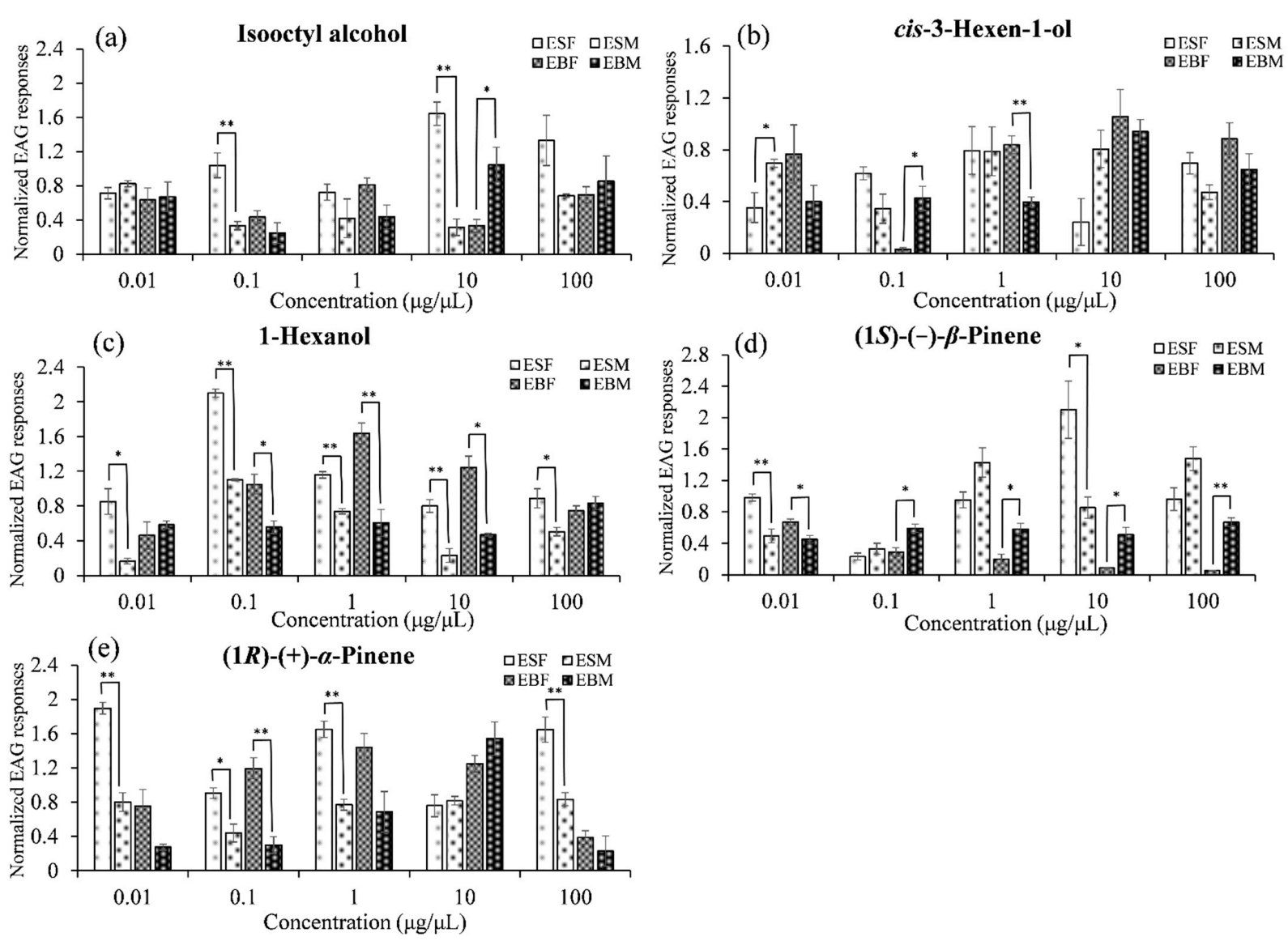

Figure 4. Mean EAG responses ( \pm SEM) of female E. scrobiculatus (=ESF), male E. scrobiculatus (=ESM), female E. brandti (=EBF) and male E. brandti (=EBM) to five compounds at five dosages $(0.01,0.1,1,10$ and $100 \mu \mathrm{g} / \mu \mathrm{L})$. (a): Isooctyl alcohol; (b): cis-3-Hexen-1-ol; (c): 1-Hexanol; (d): (1S)-(-)- $\beta$-Pinene; (e): (1R)-(+)- $\alpha$-Pinene. Asterisks indicate significant differences $\left({ }^{*}=p<0.05 ; * *<<0.01\right)$.
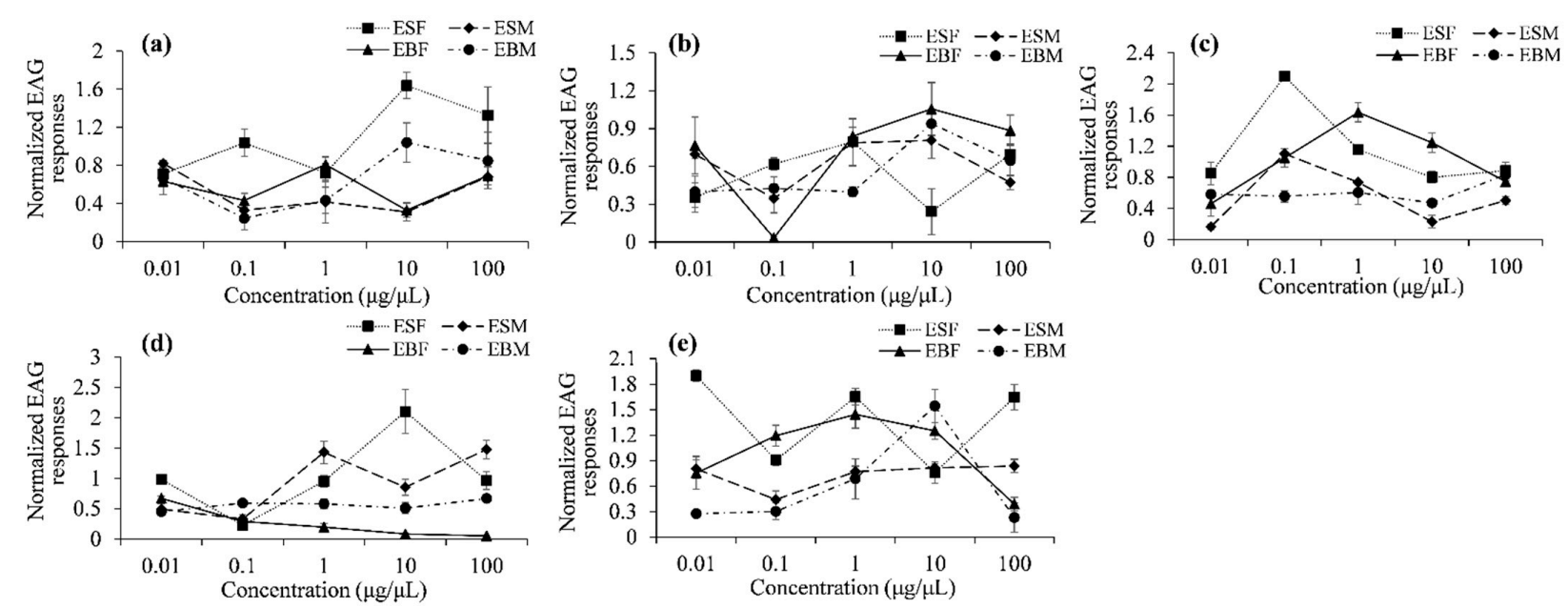

Figure 5. Dose-dependent EAG responses of female E. scrobiculatus (=ESF), male E. scrobiculatus (=ESM), female E. brandti (=EBF) and male E. brandti (=EBM) to five compounds. (a): Isooctyl alcohol; (b): cis-3-Hexen-1-ol; (c): 1-Hexanol; (d): (1S)-(-)- $\beta$-Pinene; (e): (1R)-(+)- $\alpha$-Pinene. 


\section{Discussion}

Using a comparative approach, we investigated the role of host plant-derived volatiles in the foraging behavior of adults of E. scrobiculatus and E. brandti via behavioral and antennal responses of both weevil species. Under field conditions, E. brandti adults feed on the trunk. In the field study, we found many weevils aggregated on the bare phloem of healthy and injured trees, while they preferred to feed on the tree limb of A. altissima in the large-arena experiment. In the Y-tube bioassay, female and male E. brandti significantly preferred to volatiles from phloem, regardless of tree condition. Under field conditions, E. scrobiculatus, adults feed on 1-year-old branches, perennial branches, and petioles. In the field study, we found that weevils aggregated on the bare phloem of healthy and injured trees. Adult E. scrobiculatus significantly preferred phloem volatiles over trunk volatiles in the large-arena experiment whereas in the Y-tube bioassay female and male weevils responded positively to all types of plant parts that they were exposed to. Hence, while both weevil species have the ability to discriminate against different plant parts, E. scrobiculatus responses to host plant material seem to be more variable compared with E. brandti. Overall, our findings indicate that volatile compounds of A. altissima may act as important olfactory cues in feeding behavior, particularly the volatiles from phloem for $E$. brandti.

Volatiles of different parts of A. altissima were collected by two methods (HS-SPME and dynamic headspace). It is known that plants may release more quantities of volatile chemicals when damaged by herbivorous insects [23]. In this study, the number of volatile compounds of phloem from weevil-damaged trees were greater than those identified from healthy trees, regardless of the collection method (HS-SPME or dynamic headspace method). When compared to volatiles from phloem, there were fewer volatile compounds identified in annual branches and seedling foliage. While volatile compounds emitted by $A$. altissima have been analyzed before, there has been some variability in results. For example, Mastelić and Jerković [24] analyzed the chemical composition of volatile compounds from fresh and dried leaves of young and old trees, and the main constituents were aliphatic $\mathrm{C}_{6}$-compounds and sesquiterpenes. Volatile compounds from leaves were extracted by simultaneous distillation extractor (SDE) and SPME, the component with the highest relative content was caryophyllene, and there were more compounds being detected in SPME than SDE extracts [25]. In turn, Xie [26] analyzed the volatile components of branches using the dynamic headspace method and found that $\alpha$-pinene was the most abundant component. Ji et al. [27] analyzed the volatile components of leaves by HS-SPME, and the main components were (4E)-4-hexenyl acetate and (Z)-hex-3-en-1-ol. In this study, the main component in phloem from healthy and injured trees by HS-SPME was 1-hexanol and $\beta$-caryophyllene, respectively. The main component in phloem from healthy and injured trees, seedling foliage and annual branches by dynamic headspace method was $\beta$-caryophyllene, 1 -tetradecene, $\beta$-copaene, and $\beta$-copaene, respectively. Overall, the type of collection method seems to have a strong influence on the qualitative and quantitative composition of $A$. altissima volatile compounds. In order to more precisely identify the volatile components of different parts of A. altissima, the methods of collection and analysis of volatiles need to be further refined.

This investigation provided the first evidence that E. scrobiculatus and E. brandti respond positively to volatiles emitted by their host plant. Females and males of E. scrobiculatus and E. brandti showed a significant preference for healthy phloem over clean air in the Y-tube olfactometer. Consequently, five compounds that were relatively more abundant in healthy phloem as determined by HS-SPME were selected as stimuli to test EAG responses of weevils. Due to the limitation of weevils, we did not test more individual compounds or blends. Although both weevil species could be attracted by volatiles from healthy phloem of A. altissima, there were different responses to tested compounds between them. Chemosensory genes were identified in E. scrobiculatus and E. brandti by antennal transcriptome sequencing, and the odorant binding proteins of E. scrobiculatus and E. brandti show different expression patterns [28]. It is plausible that each species shows different abilities to recognize volatiles that are involved in feeding and reproduction. Other studies have 
shown that insect behavioral responses to host volatile blends can exceed the responses to individual components [20]. Usually, blends of compounds are needed to elicit adequate behavioral responses by a foraging insect [29-31]. Consequently, we need to explore the response of weevils to host volatile blends in the future.

The morphological characteristics and physical conditions of plants may influence the feeding behavior of phytophagous insects. Dimock and Tingey [32] studied the effect of potato glandular trichomes on host acceptance behavior of Colorado potato beetle (Leptinotarsa decemlineata) larvae. They found that removal of the trichome barrier by wiping leaflets with tissue paper lead to increased incidence of feeding by larvae. Elkinton and Wood [33] studied the feeding and boring behaviors of Ips paraconfusus Lanier on the bark of a host (pine) and non-host tree (fir) species, and they found that the beetle preferred the pine to fir phloem when the outer bark was removed and the phloem was retained intact. However, no preferences were apparent for the intact pine or fir outer bark when the phloem was removed.

Under natural conditions, E. scrobiculatus and E. brandti often feed on the tree-ofheaven together, so releasing them together in the large-arena experiment was meant to simulate the field condition. E. scrobiculatus adults feed on annual branches, perennial branches and petioles in the field [12]. Here, we found that a few weevils responded to volatiles emitted by bare phloem of healthy and injured trees, and adults significantly preferred phloem from the trunk in large-arena experiment, whereas female and male weevils were significantly attracted by all the tested materials in the Y-tube bioassay. This suggests that the responses observed in the field may include factors other than plant volatiles. In the case of $E$. brandti, the observed behavior of adults in the field matched more closely the olfactory-based responses documented in this study.

\section{Conclusions}

Our findings provided an insight into the potential role that volatiles emitted by A. altissima played in the feeding behavior of E. scrobiculatus and E. brandti. This study demonstrated that (1) volatile compounds of A. altissima may act as important olfactory cues in feeding behavior, particularly the volatiles from phloem for $E$. brandti, and (2) some similarities and some differences exist in the way host-plant-derived volatiles influence the behavior of E. scrobiculatus and E. brandti. We confirmed the hypothesis that plant volatiles play an important role in the foraging behavior of E. brandti and E. scrobiculatus. Adult $E$. brandti consistently preferred volatiles from phloem of $A$. altissima, so it is vital to further analyze the responses of $E$. brandti to volatile compounds emitted by phloem. This will be helpful for developing effective plant-based attractants to monitor and potentially develop attract-and-kill systems for E. brandti.

Author Contributions: Conceptualization, X.W., J.W.; Formal analysis, X.W.; Funding acquisition, J.W.; Investigation, X.W., K.Y.; Methods, X.W., K.Y., J.W.; Writing—original draft, X.W.; Writingreview \& editing, J.C.P., J.W. All listed authors have contributed sufficiently to the project to merit inclusion as authors. All authors have read and agreed to the published version of the manuscript.

Funding: This study was supported by the National Key R\&D Program of China (2018YFC1200400) and National Natural Sciences Foundation of China (Grant No. 31770691). In addition, this work was supported by Short-term International Student Program provided research support for Postgraduates of Forestry First-Class Discipline (2019XKJS0501).

Institutional Review Board Statement: Not applicable.

Informed Consent Statement: Not applicable.

Data Availability Statement: Data sharing not applicable.

Acknowledgments: The authors thank the Forestry Bureau in Lingwu city for providing the laboratory and experimental devices.

Conflicts of Interest: The authors declare no conflict of interest. 


\section{References}

1. Bruce, T.J.A.; Wadhams, L.J.; Woodcock, C.M. Insect host location: A volatile situation. Trends Plant Sci. 2005, 10, $269-274$. [CrossRef]

2. Gause, G.F. The Struggle for Existence; The Williams \& Wilkins Company: Baltimore, MD, USA, 1934; pp. 12-26.

3. Hardin, G. The competitive exclusion principle. Science 1960, 131, 1292-1297. [CrossRef]

4. Siemers, B.M.; Schnitzer, H.U. Echolocation signals reflect niche differentiation in five sympatric congeneric bat species. Nature 2004, 429, 657-661. [CrossRef]

5. Jaenike, J. Host specialization in phytophagous insects. Annu. Rev. Ecol. Syst. 1990, 21, 243-273. [CrossRef]

6. Alonso-Zarazaga, M.A.; Lyal, C.H.C. A World Catalogue of Families and Genera of Curculionoidea (Insecta: Coleoptera) (Excepting Scolytidae and Platypodidae); Entomopraxis: Barcelona, Spain, 1999; p. 315.

7. Yang, G.J.; Yong, H.L.; Wang, X.P. The biological characters and behavior of Eucryptorrhynchus chinensis. Chin. J. Appl. Entomol. 2008, 45, 65-69.

8. Herrick, N.J.; McAvoy, T.J.; Snyder, A.L.; Salom, S.M.; Kok, L.T. Host-range testing of Eucryptorrhynchus brandti (Coleoptera: Curculionidae), a candidate for biological control of tree-of-heaven, Ailanthus altissima. Environ. Entomol 2012, 41, 118-124. [CrossRef]

9. Qin, K.X. Damage of Eucryptorrhynchus brandti to tree of heaven and its control. Chin. J. Appl. Entomol. 1996, 33, 279.

10. Yu, Q.Q.; Chen, C.; Liu, Z.K.; Sun, Y.W.; Cao, C.J.; Bao, S.; Wen, J.B. Occurrence and life-history of Eucryptorrhynchus chinensis in Lingwu, Ningxia. Chin. J. Appl. Entomol. 2012, 49, 1005-1009.

11. McAvoy, T.J.; Salom, S.M.; Yu, B.; Ji, H.L.; Du, Y.Z.; Johnson, N.; Kok, L.T. Occurrence and development of Eucryptorrhynchus brandti and E. chinensis (Coleoptera: Curculionidae) on Ailanthus altissima trees subjected to different levels of mechanical damage. Biocontrol. Sci. Technol. 2014, 24, 65-79. [CrossRef]

12. Ji, Y.C.; Gao, P.; Zhang, G.Y.; Wen, C.; Wen, J.B. Micro-habitat niche differentiation contributing to coexistence of Eucryptorrhynchus scrobiculatus Motschulsky and Eucryptorrhynchus brandti (Harold). Biocontrol. Sci. Technol. 2017, 27, 1180-1194. [CrossRef]

13. Hu, D.W.; Qiu, L.F.; Wang, J.H. Occurrence and prevention of Eucryptorrhynchus brandti in Beijing. J. Gard. Sci. Technol. 2012, 3, 24-25.

14. Yang, K.L.; Wen, X.J.; Ren, Y.; Wen, J.B. Novel trunk trap net designs for the control of Eucryptorrhynchus scrobiculatus (Coleoptera: Curculionidae). Pest Manag. Sci. 2019, 75, 2618-2626. [CrossRef] [PubMed]

15. Wu, S.H.; Wang, J.G.; Lang, X.R.; Sun, P.; Xing, L.R.; He, Z.Y. Preliminary study on integrated prevention and control technology of Eucryptorrhynchus chinensis and E. brandti in Ningxia, China. Chin. Agric. Technol. 2012, 32, 50-51.

16. Yang, P. A Preliminary Study the Artificial Raising and Control of Eucryptorrhynchus Chinensis; Beijing Forestry University: Beijing, China, 2015.

17. Yang, K.L.; Wen, X.J.; Zhang, G.Y.; Wen, J.B. Evaluation of trap designs and food attractants for trapping Eucryptorrhynchus scrobiculatus (Coleoptera: Curculionidae). Biocontrol. Sci. Technol. 2019, 29, 28-43. [CrossRef]

18. Yang, K.L.; Wen, J.B. Efficacy of trunk trap nets and insecticides applied alone and in combination for control of tree-of-heaven root weevil Eucryptorrhynchus scrobiculatus in Ailanthus altissima plantations. Forests 2019, 10, 972. [CrossRef]

19. Yang, K.L.; Wen, X.J.; Guo, W.J.; Wen, J.B. A novel adhesive trunk trap net for trapping Eucryptorrhynchus brandti (Coleoptera: Curculionidae). Pest Manag. Sci. 2019, 75, 3218-3225. [CrossRef] [PubMed]

20. Piñero, J.C.; Dorn, S. Synergism between aromatic compounds and green leaf volatiles derived from the host plant underlies female attraction in the oriental fruit moth. Entomol. Exp. Appl. 2010, 125, 185-194. [CrossRef]

21. Ruther, J. Retention index database for identification of general green leaf volatiles in plants by coupled capillary gas chromatography-mass spectrometry. J. Chromatogr. A 2000, 890, 313-319. [CrossRef]

22. Ren, L.L. Electrophysiological and Behavioral Responses of Monochamus Alternatus and Parasitoid Dastarcus Helophoroides to Semiochemicals of Several Tree Species; Beijing Forestry University: Beijing, China, 2014.

23. Paré, P.W.; Tumlinson, J.H. Plant volatiles as a defense against insect herbivores. Plant Physiol. 1999, 121, 325-331. [CrossRef]

24. Mastelić, J.; Jerković, I. Volatile constituents from the leaves of young and old Alianthus altissima (Mill.) Swingle tree. Croat Chem. Acta 2002, 75, 189-197.

25. Li, D.P.; Cao, Y.X.; Chen, N.Z.; Ma, F.; Yu, Y.X.; Li, Z.H.; Chen, H.J. Studies on volatiles compounds from leaf of Alianthus altissima extracts by simultaneous distillation extractor and solid phase micro-extraction. Plant Quar. 2013, 27, 1-5.

26. Xie, X.Y. Research on Composition and Release Regularities of VOCs from Main Landscape Plants in Xi'an; Northwest A \& F University: Yulin, China, 2016.

27. Ji, X.Y.; Yan, J.; Wang, J. Identification and comparison of volatile components from Toona Sinensis and Alianthus altissima leaves. J. Anhui Agric. Sci. 2018, 46, 179-181.

28. Wen, X.J.; Wang, Q.; Gao, P.; Wen, J.B. Identification and comparison of chemosensory genes in the antennal transcriptomes of Eucryptorrhynchus scrobiculatus and E. brandti fed on Ailanthus altissima. Front. Physiol. 2018, 9, 1652. [CrossRef]

29. Birkett, M.A.; Bruce, T.J.A.; Martin, J.L.; Smart, L.E.; Oakley, J.; Wadhams, L.J. Responses of female orange wheat blossom midge, Sitodiplosis mosellana, to wheat panicle volatiles. J. Chem. Ecol. 2004, 30, 1319-1328. [CrossRef]

30. Riffell, J.A.; Lei, H.; Christensen, T.A.; Hildebrand, J.G. Characterization and coding of behaviorally significant odor mixtures. Curr. Biol. 2009, 19, 335-340. [CrossRef] [PubMed] 
31. Bruce, T.J.A.; Pickett, J.A. Perception of plant volatile blends by herbivorous insects-finding the right mix. Phytochemistry 2011, 72, 1605-1611. [CrossRef] [PubMed]

32. Dimock, M.B.; Tingey, W.M. Host acceptance behaviour of Colorado potato beetle larvae influenced by potato glandular trichomes. Physiol. Entomol. 1988, 13, 399-406. [CrossRef]

33. Elkinton, J.S.; Wood, D.L. Feeding and boring behavior of the bark beetle Ips paraconfusus (Coleoptera: Scolytidae) on the bark of a host and non-host tree species. Can. Entomol. 1980, 112, 797-809. [CrossRef] 